\title{
Novel UWB Microstrip Antenna Structures with Defected Ground Structure
}

\author{
S. Elajoumi ${ }^{1}$, A. Tajmouati ${ }^{2}$, J.Zbitou ${ }^{3}$, A. Errkik $^{4}$, L. El Abdellaoui ${ }^{5}$ A.M.Sanchez ${ }^{6}$ \\ ${ }_{1,2,3,4}$ Laboratory LMEET FST of Settat, University Hassan $1^{\text {st }}$, Morocco \\ ${ }^{5,6}$ DICOM Laboratory, Cantabria University, Santander, Spain
}

\begin{tabular}{l} 
Article Info \\
\hline Article history: \\
Received Apr 1, 2018 \\
Revised Jun 20, 2018 \\
Accepted Jul 7, 2018 \\
\hline
\end{tabular}

Keywords:

WideBand (UWB)

FCC

Defected ground

CST microwave studio

Ansoft HFSS

\section{Corresponding Author:}

S. Elajoumi,

Laboratory LMEET FST of Settat, University Hassan $1^{\text {st }}$,

Morocco.

Email: saida.elajoumi@gmail.com

\begin{abstract}
This paper presents the design of new compact printed antennas for Ultra Wide Band applications, fed with a microstrip-line. The proposed designs consist of a patch antenna with defected ground, which are fed by $50 \Omega$ microstrip transmission line. The frequency range is $3.1-10.6 \mathrm{GHz}$ which is the Federal Communication Commission (FCC) band of UWB. The proposed antennas are easy for integration with microwave circuits. They are validated into simulation by using two electromagnetic solvers CST-MW and Ansoft HFSS. The simulated input impedance bandwidth ranging $3 \mathrm{GHz}$ to more than $14 \mathrm{GHz}$ is obtained with return loss less $-10 \mathrm{~dB}$, and exhibits good UWB characteristics. The measured parameters are good agreement with the simulation. Therefore these antennas offer excellent performance for UWB system.
\end{abstract}

Copyright () 2018 Institute of Advanced Engineering and Science. All rights reserved.

\section{INTRODUCTION}

Ultra-wide band (UWB) often considered as a recent technology in wireless communication UWB. In other word UWB transmission occupies an extremely wide bandwidth exceeding the minimum of 500 $\mathrm{MHz}$ or at least $20 \%$ of center frequency. UWB technology can be the most suitable technologies to immunity to patch interference and to revolutionize high data rate transmission. In February 2002 the Federal Communication Commission (FCC) officially released the regulation for UWB technology, with a given spectral mask for both indoor and outdoor applications in USA [1]. In accordance with the FCC regulations, the frequency band from $3.1 \mathrm{GHz}$ to $10.6 \mathrm{GHz}$ can be used for short-range and high speed wireless communications systems. The FCC power spectral density (PSD) emission limit is $-41.3 \mathrm{dBm} / \mathrm{MHz}$, so that power of UWB signal is considered as the noise for other wireless technologies. Therefore UWB communication technology became popular and extremely useful, due to various satisfying factures such as high data rate, high precision ranging, low cost and without inducing strong interference to wireless systems. UWB is regarded as very promising for vast array new applications in which it can used, for public safety, business and consumers in variety of application in wireless communication, sensor networking, radar, imaging and positioning systems.

To satisfy such requirements, many research efforts around the world have been focused on the design of antenna operated in different frequencies for various wireless transmission functions, and operation bands. Several researchers exploring RF design of UWB applications [2-4]. The UWB antenna should have extremely wide impedance bandwidth, compact size, effective in transmitting, nearly omnidirectional radiation pattern and easy fabrication on printed circuit boards (PCBs). Finally these researches give a huge boost to the design of microstrip antennas for UWB applications. The main advantages of microstrip patches 
are low profile, low height, low cost. In addition to these, they are conformable to planar and non-planar surfaces, simple and their ability be integrated with other parts of monolithic microwave integrate circuit (MMIC) designs or other UWB system. The microstrip patch elements may be square, rectangular, circular, elliptical, and triangular or any other configuration. These kinds of antennas suffer from the narrow frequency bandwidth. The impedance bandwidth of the microstrip antennas is typically limited a few percent $2 \%-5 \%$ [5]. In some applications, narrow bandwidths are desirable. However, there are several bandwidth enhancement techniques which have been adopted to improve the impedance bandwidth of these antennas. In order to detail these techniques, we will get a sneak peek to bandwidth definitions. Since the bandwidth (BW) of linearly polarized single microstrip patches is usually defined in terms of its VSWR or input impedance variation with frequency or in terms of radiations parameters. Commonly VSWR is a very popular parameter for defining the BW of a microstrip antenna. The BW of a microstrip antenna is defined as the frequency range over which the input VSWR is less than 2 but certain specifications choose 1.5.

The BW of the microstrip antenna (MSA) is given by [5]:

$$
\mathrm{BW}=\frac{\mathrm{VSWR}-1}{\mathrm{Q} \sqrt{\mathrm{VSWR}}}
$$

Where $\mathrm{Q}$ is the quality factor of the MSA and VSWR is the Voltage Standing Wave Ratio. As known the VSWR is defined in terms of input Return Loss $(\Gamma)$ by:

$$
\operatorname{VSWR}=\frac{1+|\Gamma|}{1-|\Gamma|}
$$

The expressions for approximately calculating the percentage BW of the (RMSA) in terms of patch dimensions and substrate parameters:

$$
\% \mathrm{BW}=\frac{\mathrm{Ah}}{\lambda_{0} \sqrt{\varepsilon_{\mathrm{r}}}} \sqrt{\frac{\mathrm{W}}{\mathrm{L}}}
$$

Where $\mathrm{A}$ is a constant and can take the values 180,200 and 220 .

$$
\begin{array}{cc}
\text { For } A=180 & \frac{h}{\lambda_{0} \sqrt{\varepsilon_{\mathrm{r}}}} \leq 0.045 \\
\text { For } \mathrm{A}=200 & 0.045 \leq \frac{\mathrm{h}}{\lambda_{0} \sqrt{\varepsilon_{\mathrm{r}}}} \leq 0.075 \\
\text { For } \mathrm{A}=220 & \frac{\mathrm{h}}{\lambda_{0} \sqrt{\varepsilon_{\mathrm{r}}}} \geq 0.075
\end{array}
$$

Where $\mathrm{h}$ is the substrate thickness, $\lambda_{\mathrm{o}}$ is the wavelength in the substrate, $\varepsilon \mathrm{r}$ is the dielectric constant of substrate, W, L is the width and length of patch dimension.

Overall, there are several methods of BW expansion, such as using notches or slots on patch antenna with different shapes as square slot [6], U-slot [7], circular slot [8], T-shaped slot [9] ... etc; using dielectric substrates with high permittivity [10], increasing the substrate thickness, use of various impedance matching and feeding techniques [11], [12]. Another technique to increase significantly the slot of the planar monopole antenna fed by a coplanar waveguide is to use tapered ring slot antenna [13], tuning stub [14], L-probe feeding [15]. Well as other methods of microstrip elements can also be used to increase the bandwidth [16], [17].

In this work, we present novel UWB antennas which were investigated. These proposed antennas are printed on microstrip substrate with defected ground structure to match the input impedance, large bandwidth and stable radiation patterns that can operate over a wide frequency band. Details of the antenna designs, simulated and measured results are presented and discussed. 


\section{UWB ANTENNA DESIGN}

Figure 1 shows the geometry and configuration of the final antennas. The proposed antennas are fed by a microstrip line with a characteristic impedance of $50 \Omega$ on an FR4 substrate with a thickness of $1.6 \mathrm{~mm}$, relative permittivity of 4.4 and a loss tangent of 0.025 .

The antenna structure designed is based on triangular radiator patch. The proposed antennas have undergone a number of changes at the origin, to widen the narrow bandwidth, we have applied several techniques: modification of geometry of triangular shape by using the stepped cut corner with three steps and defected ground with a semicircular shaped ground and a rectangular slot below the microstrip line and by associating an additional patch Figure 2 presents the evolution of the proposed antennas. The final dimensions obtained after many series of optimization by CST are listed in Table 1.
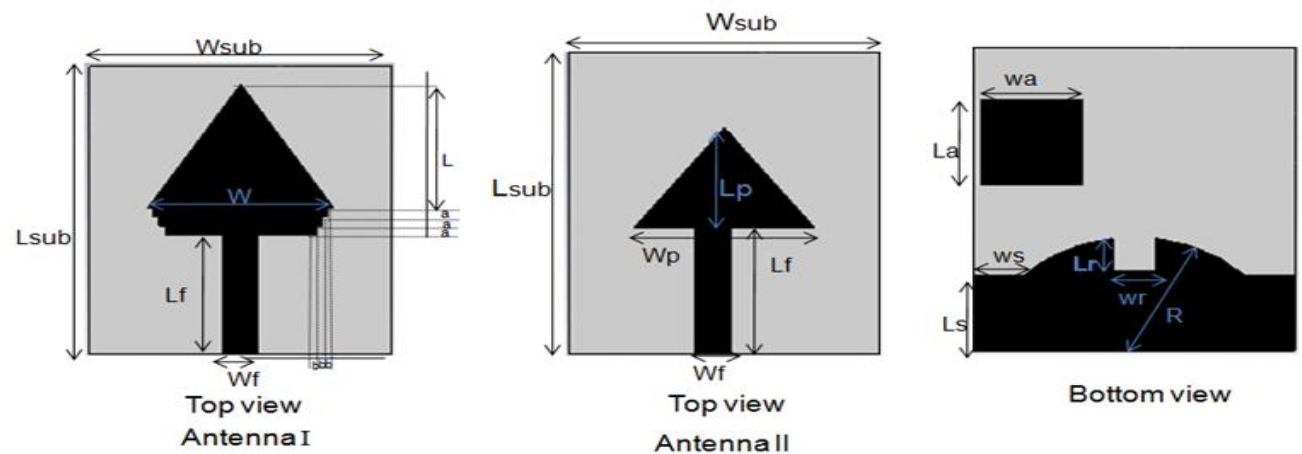

Figure 1. Geometry of the proposed antennas, Top view, Bottom view

Table1. Optimized dimensions of the proposed antennas

\begin{tabular}{cccc}
\hline Parameter & Value $(\mathrm{mm})$ & parameter & Value $(\mathrm{mm})$ \\
\hline Wsub & 24 & Lsub & 28 \\
W & 16 & Wa & 8 \\
L & 11 & La & 9 \\
Lf & 13.25 & $\mathrm{R}$ & 12 \\
Wf & 3 & $\mathrm{Wr}$ & 3.5 \\
Ls & 8 & Lr & 3.5 \\
Ws & 4 & $\mathrm{a}$ & 1 \\
Lp & 10 & $\mathrm{~b}$ & 0.5 \\
Wp & 12 & & \\
\hline
\end{tabular}

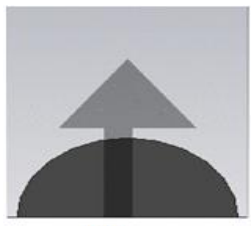

(a)

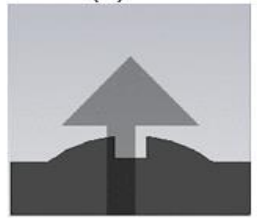

(c)

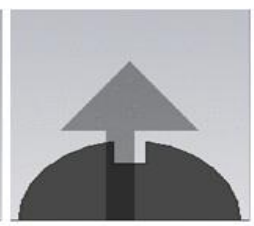

(b)

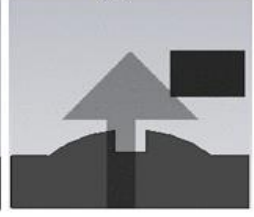

(d)

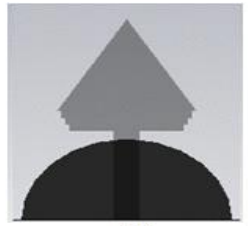

(a)

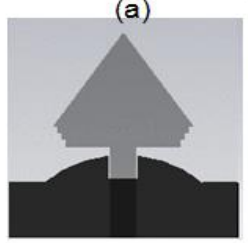

(c)

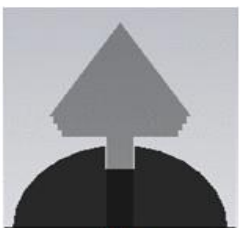

(b)

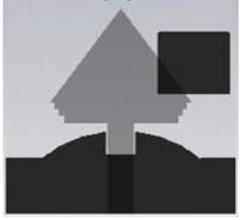

(d)

Antennall

Antennal

Figure 2. Design evolutions of the proposed antennas 


\section{SIMULATION RESULTS AND DISCUSSIONS}

The reflection coefficient simulation results of all designs of the proposed antennas Antenna I and Antenna II are shown in Figure 3. The simulated reflection coefficient of design (a) is showing good matching at the first bandwidth is from $3 \mathrm{GHz}$ to $4.5 \mathrm{GHz}$ with reflection coefficient less than -10dB while the second bandwidth is from $6 \mathrm{GHz}$ to $10 \mathrm{GHz}$ for Antenna I, thus for Antenna II the simulated bandwidth is $6 \mathrm{GHz}(3.7 \mathrm{GHz}$ to $9.7 \mathrm{Ghz})$ with a reflection coefficient less than $-10 \mathrm{~dB}$,so to increase the impedance bandwidth so more, we have inserted a semicircular shaped ground with a rectangular notch defined by (Wr $\mathrm{x}$ Lr) printed in the bottom side, and by associating an additional patch as shown in Figure 2 (d), it permits to improve and to enlarge the bandwidth until more than $12 \mathrm{GHz}$ and to get the best resonant frequencies.

To compare the obtained results by using CST-MW, we have used another 3D electromagnetic solver which is HFSS. Figures 4 and 5 illustrate the reflection coefficients and VSWR obtained by simulation for the optimized structure. It is clearly observed that the simulation results in CST-MW and HFSS are in agreement.
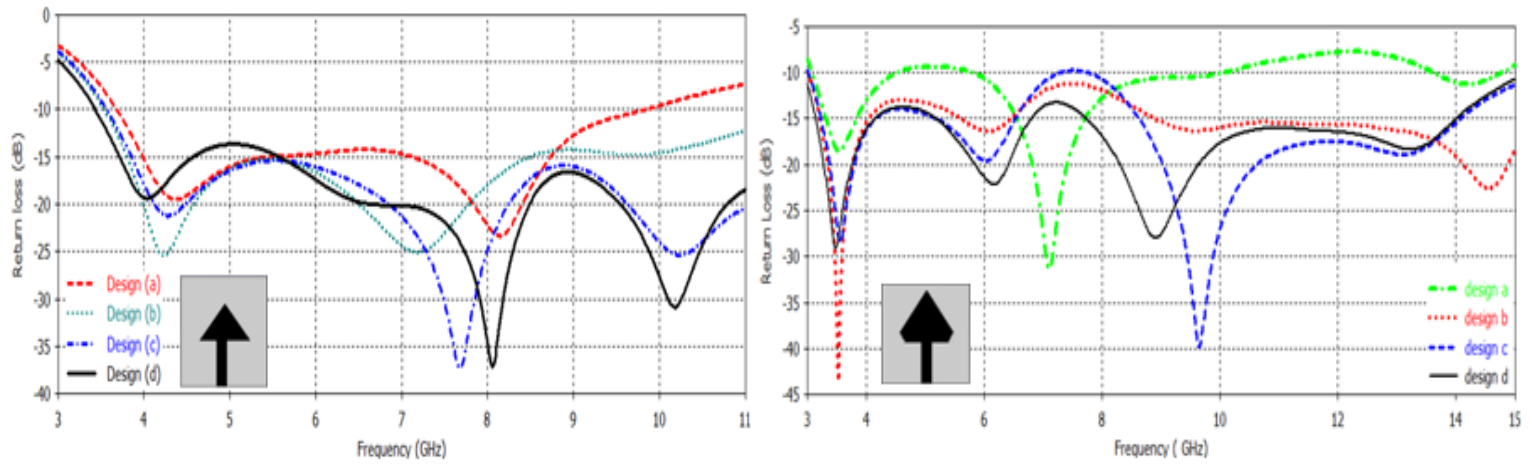

Figure 3. Reflection coefficient for different designs of the proposed antennas
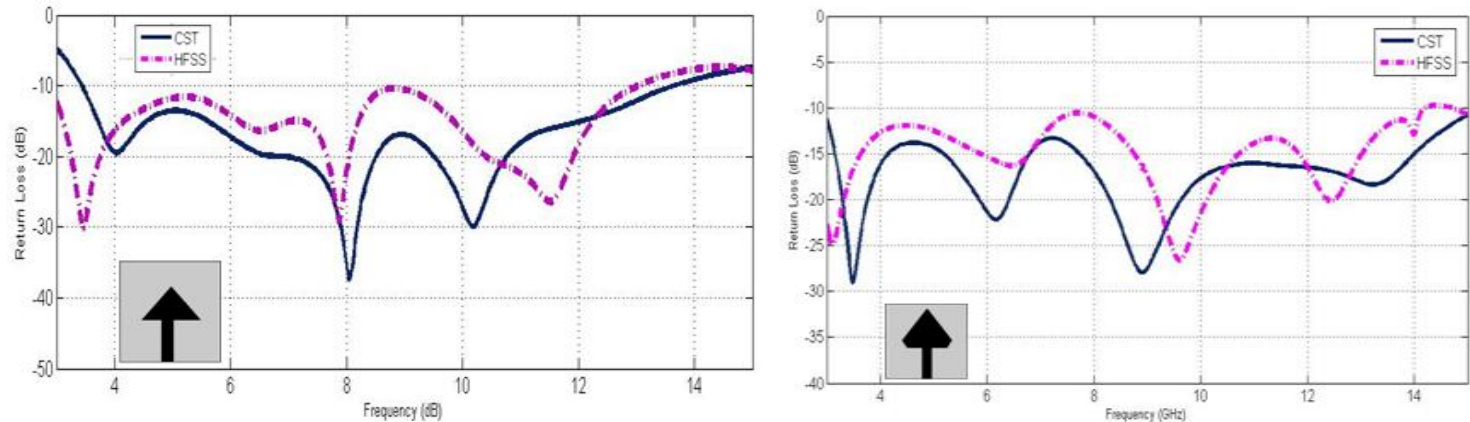

Figure 4. Comparison between reflection coefficients obtained by HFSS and CST-MW for the proposed antennas
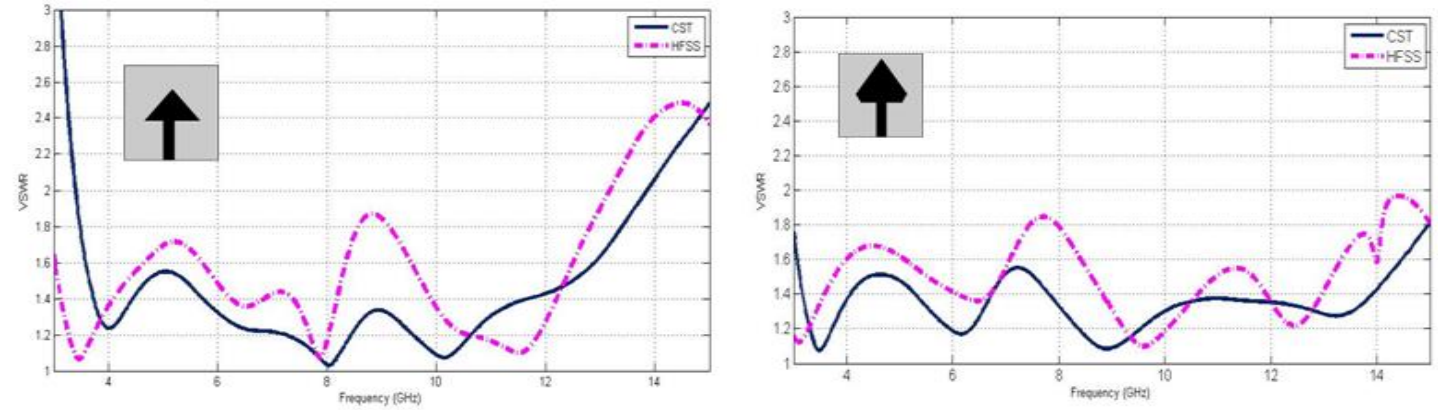

Figure 5. Comparison between VSWR obtained by HFSS and CST-MW of the proposed antennas 
The Figure 6 presents the simulated gain for proposed antennas versus frequency for different values of frequencies along the operating frequency band. It is clearly observed that simulation results provide the maximum gain variation is about $3.6 \mathrm{dBi}$ for Antenna I and 4.3dBi for Antenna II.

Figure 7 illustrates the simulated surface current distribution of the proposed antennas at $3.1 \mathrm{GHz}, 6$ $\mathrm{GHz}$ and $10.6 \mathrm{GHz}$ it has been revealed through observation that the distribution of current is heavily concentrated in the feeding line and around the notch on the bottom of the patch for all frequencies. Thus it's much stronger in lower band frequencies than the upper band frequencies.
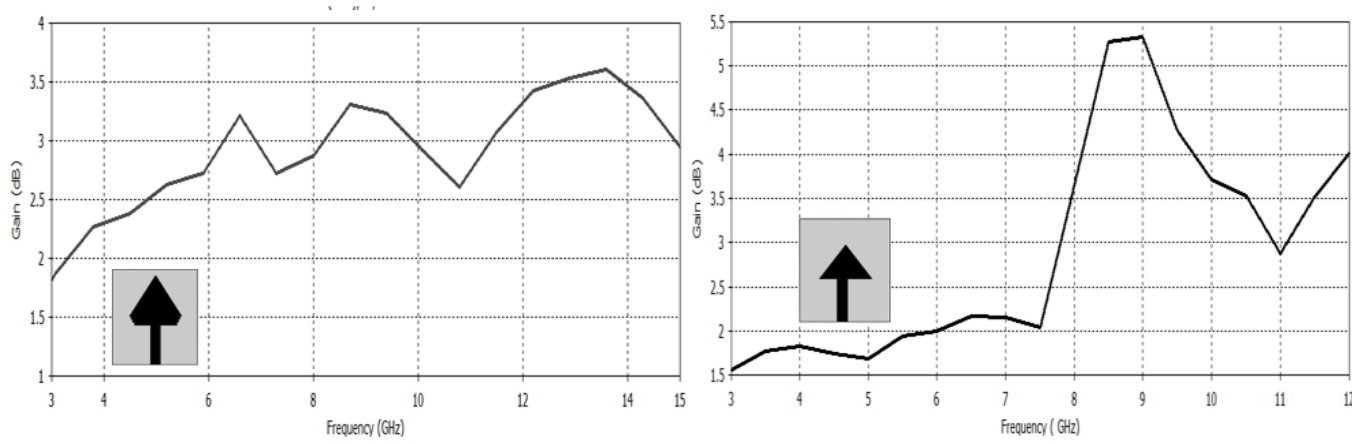

Figure 6. Simulated Gain of the proposed antennas
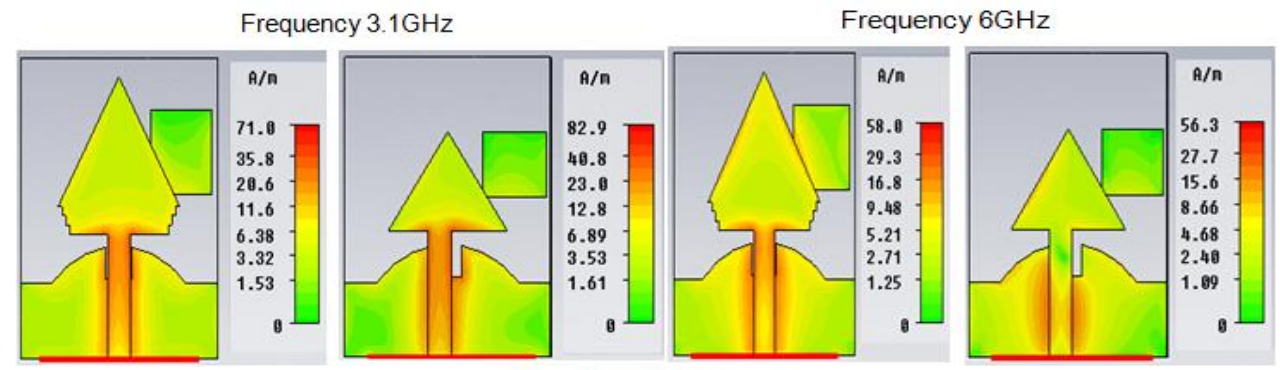

Frequency $10.6 \mathrm{GHz}$
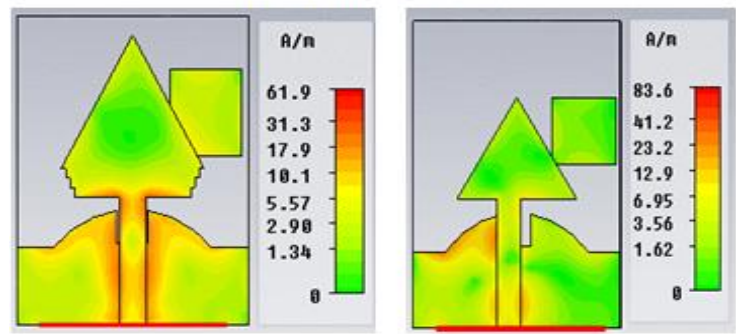

Figure 7. Surface current distribution of the proposed antennas at $3 \mathrm{GHz}, 6 \mathrm{GHz}$ and $10.6 \mathrm{GHz}$

Fifure 8 shows the simulation 2D Far-field radiation patterns of the antennas on E-plane and $\mathrm{H}$ plane at $3.1 \mathrm{GHz}, 6 \mathrm{GHz}$ and $10.6 \mathrm{GHz}$. In E-plane the simulated results shows an almost omnidirectional in low frequencies which are $3.1 \mathrm{GHz}, 6 \mathrm{GHz}$ and lose the omnidirectionality for high frequency which is 10.6 $\mathrm{GHz}$. In H-plane the radiation patterns is nearly bidirectional for all frequency bands. 

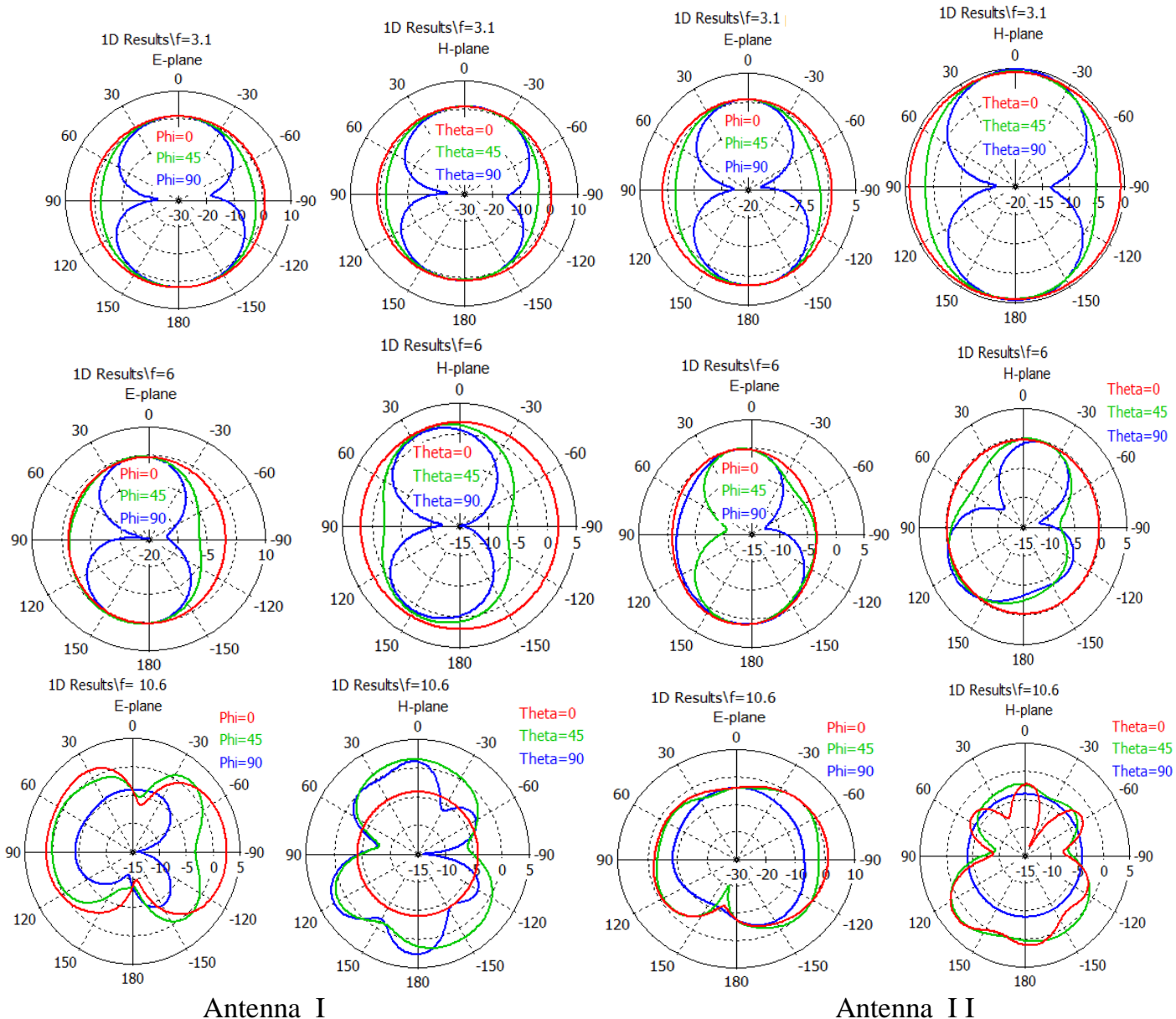

Figure 8. Simulated radiation patterns for the proposed antennas at different frequencies on E-plan and H-plan: $(3.1 \mathrm{GHz}, 6 \mathrm{GHz}$ and $10.6 \mathrm{GHz})$

\section{ACHIEVENMENT AND MEASUREMENT RESULTS}

We fabricated the proposed antennas by using LPKF machine, after the design and optimization by using CST and HFSS, the prototype of the investigated antennas are achieved and measured to verify the performance of the simulation results. The prototype of the proposed antennas are illustrated in Figure 9. We measured the reflection coefficient using the Agilent Technologies 2-port VNA N5230A. The calibration which we have used is the $3.5 \mathrm{~mm}$ from Agilent technologies. Figure 10 shows the simulation by using two electromagnetic solvers CST-MW and Ansoft HFSS and measured reflection coefficients results. It can be observed that the simulation results are in agreement with measurement in term of bandwidth results. Besides, the proposed antennas have wideband performances covering the entire UWB frequency band. The difference between the measurement and simulation results is due to uncertainty in substrate thickness and dielectric constant.

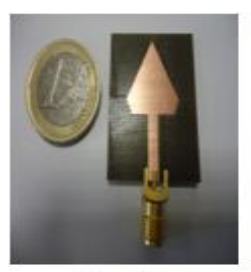

Top view

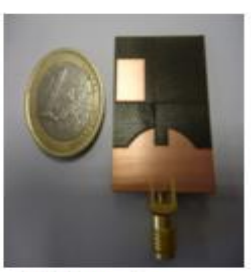

Bottom view

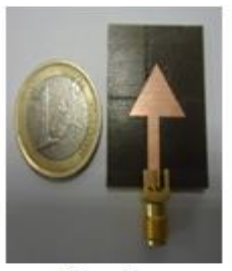

Top view

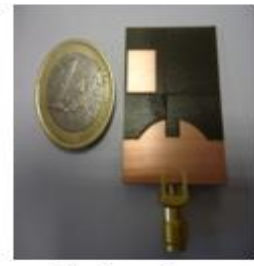

Bottom view

Antenna I

Figure 9. Photographs of the achieved UWB antennas 

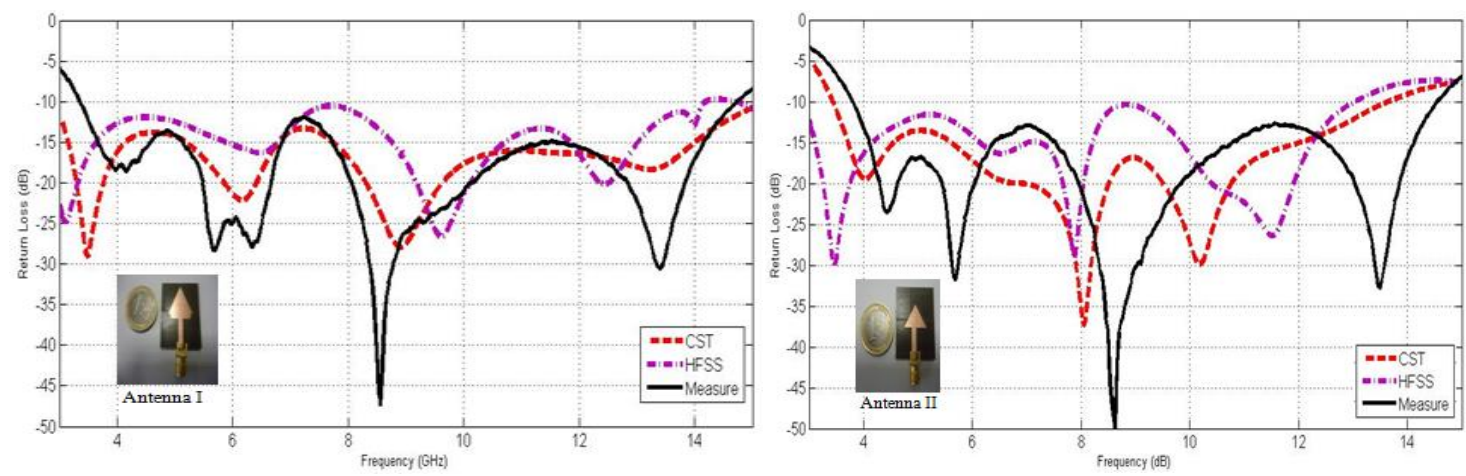

Figure 10. Simulated and measured reflection coefficients vs frequency of the proposed antennas

Table 2 presents the summaries the performances and compares the proposed antennas to recently published UWB antennas.

Table 2. Comparison between recently proposed antennas and these antennas

\begin{tabular}{|c|c|c|c|c|c|c|}
\hline \multicolumn{2}{|c|}{ References } & $\begin{array}{l}\text { Substrate } \\
\text { material }\end{array}$ & $\begin{array}{l}\text { Methode for } \\
\text { improve bandwidth }\end{array}$ & $\begin{array}{l}\text { Operating } \\
\text { bandwidth }\end{array}$ & $\begin{array}{l}\text { Structure } \\
\text { Size }\left(\mathrm{mm}^{2}\right)\end{array}$ & Gain \\
\hline \multicolumn{2}{|l|}{ [8] } & $\begin{array}{l}\text { Rogers RT } \\
\text { Duroid } \\
55880\end{array}$ & $\begin{array}{l}\text { Patch with two } \\
\text { steps and a circular } \\
\text { slot with partiel } \\
\text { ground }\end{array}$ & $3-12.5 \mathrm{GHz}$ & $50 \times 41$ & $2-5$ \\
\hline \multicolumn{2}{|l|}{ [17] } & RT-Duroid & Double I Slot & $7.2-12 \mathrm{GHz}$ & $34.2 \times 29.2$ & $2-3.5$ \\
\hline & FR4 & Finger-Shaped & $3-12 \mathrm{GHz}$ & $40 \times 35$ & $2-6$ \\
\hline & & FR4 & Tuning stub & $3-11.5 \mathrm{GHz}$ & $28 \times 21$ & $2-7$ \\
\hline \multirow{2}{*}{ 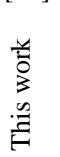 } & $\begin{array}{l}\text { Antenna } \\
\text { I }\end{array}$ & FR4 & $\begin{array}{l}\text { Defected ground } \\
\text { structure }\end{array}$ & $3.5-14.5 \mathrm{GHz}$ & $27 \times 24$ & $2-3.6$ \\
\hline & $\begin{array}{l}\text { Antenna } \\
\text { II }\end{array}$ & FR4 & $\begin{array}{l}\text { Defected ground } \\
\text { structure }\end{array}$ & $3.6-14.5 \mathrm{GHz}$ & $24 \times 24$ & $1.5-5.3$ \\
\hline
\end{tabular}

\section{CONCLUSION}

In this study, microstrip UWB monopole antennas have been developed, analyzed and validated for UWB band applications. The defected ground structure plays an important role in the design of compact and high performance microstrip antenna. The proposed antennas have successfully achieved and improved with a wide bandwidth, in which UWB frequency spectrum covers the range from 3.4 to $14.5 \mathrm{GHz}$ with excellent performance in term of return loss. The radiation patterns have good stability over the entire frequency band defined by FCC. The simulated results are nearly in agreement with the measured results in term of reflection coefficients. These kinds of antennas can easily be integrated with RF/microwave circuits for compact design and fabricated at a very low manufacturing cost.

\section{REFERENCES}

[1] T. W. Barrett. History of ultraWideband UWB radar and communications: Pioneers and innovators," in Proc. Progress in Electromagnetics Symposium, July 2000.

[2] Xian Ling Liang .Ultra-Wideband Antenna and Design. chapter 7, INTECH ,2012.

[3] Rezaul Azim and Mohammad Tariqul Islam. Printed wide slot Ultra-Wideband Antenna. chapter 7, INTECH, 2013.

[4] F. C. Commission.Revision of Part 15 of the commission's rules regarding ultra-wideband transmission systems, FIRST REPORT AND ORDER. ET Docket 98-153, FCC 02-48, pp. 100-118, 2002.

[5] C. A. Balanis .Antenna Theory third edition - Analysis and design .2005: 811-870

[6] Liu, Y.F., Lau, K.L., Xue, Q., and Chan, C.H. Experimental studies of printed wide-slot antenna for wide-band applications. IEEE AntennasWireless Propag. Lett. 2004; 3(1): 273-275.

[7] M. Koohestani and M. Golpour . U-shaped microstrip patch antenna with novel parasitic tuning stubs for ultra wide band applications. Microw. Antennas Propag. 4; 2010: 938-946.

[8] Osama Haraz and Abdel-Razik Sebak. UWB Antennas for Wireless Applications. chapter 6, 2013, Haraz and Sebak, licensee InTech. 
[9] M. Naser-Moghadasi, R. A. Sadeghzadeh, T. Sedghi, T. Aribi, and B. S.Virdee . UWB CPW-Fed Fractal Patch Antenna With Band-Notched Function Employing Folded T-Shaped Element. IEEE Antennas and Wireless Propagation Letters .2013; 12.

[10] X. Tang, H.Wong, Y. Long, Q. Xue, and K. L. Lau. Circularly polarized shorted patch antenna on high permittivity substrate with wideband. IEEE Transactions on Antennas and Propagation. 2012 ; 60(3): 1588-1592.

[11] Njeri P. Waweru, D.B.O. Konditi, and P.K.Langat. Variation of Input Impedance with Feeding Positionin Probe and inset-Fed Microstrip Patch Antenna. Innovative Systems Design and Engineering.2012;3 (7) .

[12] K. Mandal, S. Sarkar, and P.P. Sarkar. Bandwidth Enhancement of Microstrip Antennas by Staggering Effect. Microwave Opt. Technollett, 2011; 53 (10) .

[13] V.A. Shameena, S. Mridula, Anju Pradeep, Sarah Jacob, A.O. Lindo, P. Mohanan. A compact CPW fed slot antenna for ultra wide band applications. AEU - International Journal of Electronics and Communications. March, 2012; 66 (3): 189-194

[14] J. William and R. Nakkeeran . CPW-Fed UWB Slot Antenna with Triangular Tuning Stub" International Journal of Computer and Electrical Engineering. August, 2010; 2 (4).

[15] Kai Xu Wang, Li Gao, Hau Wah Lai, Kwok Kan So, Hang Wong, Quan Xue, Xiu Yin Zhang . Multilayer WideBand Patch Antenna Using L-probe and Structure. High Speed Intelligent Communication Forum (HSIC), 4th International , 10-11 May 2012.

[16] Rashid A. Fayadh, Mohd Fareq A. Malek, Hilal A. Fadhil, Fwen Hoon Wee. Planar Finger-Shaped Antenna Used in Ultra-Wideband Wireless Systems. TELKOMNIKA (Telecommunication, Computing, Electronics and Control). 2014; 12(2): 419- 428 .

[17] Hassan M. Elkamchouchi , Rateba A. Salem. Microstrip Patch Antenna with Double I Slot for Wide Band Applications. International Journal of Electronics and Communication Engineering (IJECE). March 2016; 3 (3). 